\title{
Rankings Have Proven the Need to Develop Sociopsychological Competences in Technology Students
}

\author{
Tatiana Magera ${ }^{1, *}$ \\ ${ }^{1}$ Moscow State University of Civil Engineering, Yaroslavskoe shosse, 26, Moscow, 129337, Russia
}

\begin{abstract}
Urban planning is deemed to improve the living standards and the life satisfaction of urban residents. However, it does not always work this way. It is anticipated that the formation and development of sociopsychological competencies in urban planning professionals can boost both the living standards and life satisfaction. In the article, the author presents the findings of the study of several international rankings; she also offers some definitions, and formulates a number of probable reasons for the insufficient development of sociopsychological competencies in urban planning professionals. The author also offers several actions, aimed at the prevention of social dissatisfaction of urban residents' within the framework of the sociopsychological competence.
\end{abstract}

\section{Introduction}

The research literature draws particular attention to the sociopsychological competence for the reasons, inherent to the essence of the human life, which can be defined as communication. According to L.A. Petrovskaya, "the nature of any human activities is interpersonal". She has also compiled a generalized definition of the communication competence as "the development of the adequate understanding by any person of his/her personal self and his/her psychological potential, the potential of his/her partner, as well as the adequate understanding of the situation and the communication objective." [1] In her works, the author studied the diversity of social contacts, typical for investment and construction industries, and the relevance of the sociopsychological competence for urban planners $[2,3,4]$. It is common knowledge that the sociopsychological competence, being a set of competencies, represents an integrative index, bringing together individual psychological features, which facilitate efficient interaction with other individuals. Builders, architects, economists, IT specialists, and managers - those who are involved in the shaping of contemporary cities - are integrated into the external social environment, and this fact serves as the precondition for their activity, which cannot generate any "team-free" results $[5,6]$. Although the urban planning history features several "team-free one-aloners" as the founders of towns and cities, in the end, the heremitical lifestyle of one person may serve as the unity driver for the following generations. Thus, the retreat of Sergius, abbot of

*Corresponding author: mageratatiana@mail.ru 
Radonezh, built in the remote woodland in the 14th century, developed into a large monastery, which brought the nearby suburbs/settlements together and obtained the status of a town (Sergiyev Posad) in 1782 under the Decree issued by Catherine the Great.

\section{Materials and methods}

The words "competency" and "competence" take origin from the Latin words "competens" (suitable, appropriate or legal) and "compete" (to be applicable or capable). In the context of professional activities, competencies are understood as the availability and extent of pronouncement of professionally valuable features (qualities); a person demonstrates the extent of maturity of these qualities, which make it possible for him/her to establish him/herself as a proficient person, good at interacting with other individuals and capable of establishing and developing constructive social contacts ("able to convince", "able to come to terms", "easy going"). In other words, if we refer to the Latin origin of these terms, a competent specialist or executive is able to efficiently solve professional problems, arising in the social domain.

The assessment of efficiency of social interaction is the basic precondition for the efficiency improvement in terms of any activity (management, services provision, client support, etc.) For example, the efficiency of social management is assessed by criteria, indices, and benchmarks. A criterion is the basis for reasoning, or a specific feature, which serves as the basis for the assessment or classification, identification of significance and condition of the object. An index demonstrates the level of efficiency; it is applied in qualitative assessments. A benchmark represents a qualitative and quantitative condition of an object/process, qualifying under each public characteristic and expectation [7].

The author focuses her attention on the study of social efficiency, understood as the satisfaction with life quality, demonstrated by interacting individuals. The notion of the social activity encompasses:

1. The social efficiency in the framework of the nationwide urban policy, because it is a means to find out the extent of the end user's satisfaction with an urban planning product;

2. The social efficiency in the framework of the educational environment, or a university of technology, as it is a means to assess the quality of educational services, involving the formation and development of sociopsychological competence;

3. The social efficiency of pre-university training, as it is a means to find out the career mindsets, impacting the process and result of higher education, that is, the satisfaction with the urban life.

If considered within the framework of an urban policy, the social efficiency takes account of the following three basic criteria [8]:

- Diffusion of results (it contemplates the analysis of the number of citizens improving their statuses as a result of the policy implementation);

- Social engagement (involvement of residents in the process of development, decision making, and control over decision implementation);

- Social prospects (the extent of coherence between these processes and major processes which are underway within the framework of the civilization and the state).

Each of the three criteria comprises a subjective assessment component; it contemplates a contact between urban residents and municipal authorities, acting as social interaction partners. Therefore, if the constructive background, benevolence, commitment to results, trust and social sensibility are in place, the assessment of efficiency of social interaction by the "Diffusion of results" criterion may be completely different from the assessment made in the absence of any positive interaction in the process of discussing the urban housing. In the latter case, attention is focused on negativism; target setting turns less productive and shifts from problem solving to confrontation, and partnership converts into competition. 
The social efficiency, if analyzed before the enrollment at a university of technology and in the process of study there, represents a supplementary subject of research based on the list of questions, including the following ones:

1. In what way does the sociopsychological competence of applicants influence the successful passing of high school and university examinations? It is common knowledge that mental intelligence does not make a difference in terms of personal, professional or educational success. In most cases, social intelligence, composed of sociopsychological competencies, is the core pre-condition.

2. Do we need to launch any courses aimed at the generation and development of sociopsychological competencies at a university of technology? The issue of economic expediency arises here, as this process contemplates the introduction of a new course; the issue of methodology is also here, as the new course will replace other courses or will be integrated into them; the issue of personnel employment arises here, as any extracurricular activities are off the payroll of lecturers; the issue of education arises here, if this course is treated as supplementary but necessary due to the fact that urban development specialists do not have any sociopsychological competencies.

3. What arguments back the idea of developing the sociopsychological competence at a university of technology, offering/not offering degrees in civil engineering? [9].

For answers to these questions in this article are used indicators of the world rankings. It is anticipated that (1) the practical implementation of efficient social interaction, which is feasible if and when the sociopsychological competence is in place, (2) the study and the training of social and psychological skills are both based on the criteria, which are the registered results of versatile research undertakings. Rankings were widely used in the recent decades of the $20^{\text {th }}$ century; they represented the assessment of pre-selected ranked factors on the basis of the criterion of importance or significance:

1. Progress in International Reading Literacy Study, PIRLS [10]

2. Third International Mathematics and Science Study, TIMSS [11]

TIMSS and PIRLS conducts regular international comparative assessments of student achievement in mathematics and science (TIMSS) and in reading (PIRLS) in more than 60 countries; together comprise the core cycle of studies for IEA - the International Association for the Evaluation of Educational Achievement. TIMSS and PIRLS results include: easuring the effectiveness of their educational systems in a global context; identifying gaps in learning resources and opportunities; pinpointing any areas of weakness and stimulating curriculum reform; measuring the impact of new educational initiatives; training researchers and teachers in assessment and evaluation. TIMSS and PIRLS also collect extensive data about the contextual factors that affect learning, including school resources, student attitudes, instructional practices, and support at home. This information can be examined in relation to achievement to explore factors that contribute to academic success [12].

3. International Civic and Citizenship Education Study, ICCS [13, 14]

The study collects a rich array of contextual data about the organization and content of civic and citizenship education in the curriculum, teacher qualifications and experiences, teaching practices, school environment and climate, and home and community support. Mindful of the new and emerging challenges evident in today's world, the study aims to improve countries' understanding of issues such as students' role with respect to global citizenship, environmental sustainability, social interactions at school, and the use of new social media for civic engagement. [13]

4. Programme for International Student Assessment, PISA [15]

The Programme for International Student Assessment (PISA) is a triennial international survey which aims to evaluate education systems worldwide by testing the skills and 
knowledge of 15-year-old students. The main focus was on science, an increasingly important part of our economic and social lives. [15]

5. Academic Ranking of World Universities, ARWU [16]

Starting from 2003, ARWU has been presenting the world Top 500 universities annually based on a set of objective indicators and third-party data. ARWU has been recognized as the precursor of global university rankings and the most trustworthy league table. ARWU adopts six objective indicators to rank world universities. More than 1200 universities are actually ranked by ARWU every year and the best 500 universities are published. [16]

6. The Social Progress Index, SPI [17]

The SPI measures the well-being of a society by observing social and environmental outcomes directly rather than the economic factors.

\section{Results}

Russian schoolchildren demonstrate high results (not sociopsychological competence):

- $\quad$ reading/understanding capabilities is performed of texts (PIRLS)

- natural sciences and math (TIMSS)

Russian schoolchildren demonstrate average results (partially sociopsychological competence)

- $\quad$ citizenship education study (ICCS)

Russian schoolchildren demonstrate low results (partially sociopsychological competence and sociopsychological competence):

- $\quad$ problem solving skill or ability (PISA)

- the experience of social interaction (PISA)

- the preparation for adult living (PISA)

- $\quad$ the public welfare (SPI)

Higher education not aimed at development of sociopsychological competence directly (according to the selected ratings).

Perhaps, in the pre-university period, mental intelligence compensates for insufficiency of sociopsychological competence. But after - not.

\section{Discussion}

At the pre-university level, conditions for the successful integration into the social environment represent the mastery of the main types of human activities, including communication, work, play, and studies. Verbal skills, abilities to build understanding with an interlocutor develop in the course of text manipulations at high school. The research into reading/understanding capabilities is performed within the framework of PIRLS, which is an international project [10]. Russian schoolchildren traditionally demonstrate high results, and in 2006, Russia was ranked first among several countries. According to the findings of the TIMSS, Russia is among the top ten countries in terms of the quality of education provided in natural sciences and math $\left(8^{\text {th }}\right.$ and $11^{\text {th }}$ grades $)$ [11]. The International Civic and Citizenship Education Study, ICCS [13], serves to assess the preparedness of schoolchildren to the social role of a citizen. Russia takes the $22 \mathrm{~d}$ position here.

Contemporary trends in the assessment of educational attainments are found in the research project entitled PISA [15]. PISA monitors the following four skills: reading literacy, mathematical literacy, scientific literacy and computer literacy. Back in 2003, one more skill was added, that was problem solving literacy. In 2012, a novel type of problems was introduced into the system of mass testing and assessments. Interactive problems 
contemplate the study of a new object - a virtual device (for example, an MP3 player) and the provision of answers to the questions about the peculiarities of its operation. The skills assessed within the framework of mathematical literacy include the ability to identify and understand the role of mathematics in the environment, the ability to express well-grounded mathematical arguments and to use math to satisfy personal needs, typical for a creative, empathic and thoughtful person. Scientific literacy means the ability to take advantage of the research information, to identify problems and to make well-grounded conclusions, which are necessary to understand the essence of the environment and the changes forced by the human activities, and to make rightful decisions. Reading literacy means the ability to reflect on written texts, to work with their content to attain reading objectives, to obtain the knowledge and to pursue the opportunities, to be proactively involved in the public life. Reading skills and literal understanding of text are not assessed here; rather, the ability to reflect on the essence of texts and to employ the information extracted from them is exposed to evaluation. The problem solving competence means the ability to employ cognitive abilities to solve inter-disciplinary problems, if the solution is not evident at first sight.

PISA tests are not limited to certain areas of knowledge; rather, they serve to check systemic and inter-disciplinary abilities and to track the ability to apply the experience accumulated in the course of social interaction. The materials, employed within the framework of this methodology, do not represent a mere set of data to be learned; any teaching material is updated in the course of solving practical problems in the social context. Russia takes the leading positions in terms of its mathematical and scientific literacy, but it is a little behind in terms of its problem solving competence. Therefore, secondary school attainments are never limited to school grades. PISA's ranking does not insist on shifting the priorities from the study of extensive amounts of information to the preparation for adult living.

Numerous international rankings, aimed at the monitoring of higher education institutions, fail to assess sociopsychological competencies; therefore, the correlation between the latter and the social efficiency of graduates would be impossible to trace, save the indirect assumptions and confirmations. Developers of international rankings focus on the research attainments (citation indices) and reputation in the research/employment community. These criteria can hardly be used to assess the quality of educational activities at particular universities, and sometimes the educational activity is not assessed at all. The Academic Ranking of World Universities (ARWU) is based on the number of Nobel prize/Fields medal winners among the university graduates; therefore, this ranking can hardly be used to study the quality of higher education [16].

A graduate of a university of technology has a number of professional and universal competencies. It stands to reason that his/her sociopsychological competencies developed naturally, without the impact produced by the special environment or the educational process. Natural conditions, nurturing sociopsychological competencies, comprise the structural components of socialization, the integration of a personality into the society, the assimilation of elements of culture, norms, values and behavioural patterns. The socialization process is particularly intensive when a person is young, although it accompanies him/her throughout his/her life. G.M. Andreeva, B.P. Bitinas, L. Kolberg, I.S. Kon and others believe that the core content of socialization consists in social ideas, symbols, values and mindsets, social skills and behavioural patterns. Education is an importation socialization institution; at universities and colleges, young people master the substantive components of socialization, which helps graduates to successfully adapt to and efficiently participate in professional activities. The efficiency of social interaction, being a consequence of natural socialization at a higher education institution, boosts the social 
efficiency demonstrated in the process of the urban policy development; it does not require any purposeful study of sociopsychological competencies.

The rankings, reflecting satisfaction with the quality of life, include the Social Progress Index, an integrated index compiled within the framework of the international research project entitled The SPI. It measures the attainments of countries from the viewpoint of their public welfare and social progress [17]. Its compilers consider the notion of social progress as a most important area of research in sociology, psychology, economics, and government management. The values of social development are considered as an alternative to the values of economic development. The index does not cover such economic values, as GDP (gross domestic product) or GNI (gross national income). The index is designated for the assessment of the national public welfare; it represents a combination of opinion poll findings $(12 \%)$; expert assessments made in the area of development (25\%); and statistics provided by the international organizations $(61 \%)$. The index covers over fifty factors clustered into the three main groups:

1. Basic human needs (food, access to water, electricity, sanitation, basic medical aid, housing, personal safety);

2. Fundamentals of the human welfare (access to basic knowledge, information, communication means, population literacy, healthcare, environmental sustainability);

3. Development opportunities (personal and civil rights, respect for rights, independent decision making, opportunities to unlock the potential).

As of 2015, Russia was 72nd in this ranking (while Moldova was $70^{\text {th }}$, Ukraine $-62^{\text {nd }}$, Romania $-50^{\text {th }}$, Panama $-41^{\text {st }}$, Costa Rica $-28^{\text {th }}$, USA $-16^{\text {th }}$, New Zealand $-5^{\text {th }}$, Norway$\left.1^{\text {st }}\right)$ [17]. Given the fact that economic indices are excluded from this ranking, Russia's position there makes us think about the reasons for and the consequences of the country's social progress. We may solve the problem of the life quality improvement by resetting secondary and higher education priorities and introducing a well-balanced approach to the process of generation of professional and universal competences.

\section{Conclusions}

At universities of technology, any socially valuable experience is transferred under the "foreman to apprentice" principle applied in the process of teaching and learning technical disciplines. Universities of technologies offer limited opportunities for the development of sociopsychological competencies, including social sensibility, appropriate behavior in conflicts, ability to maintain partnership relations, ability to apply emotional intelligence and self-organization capabilities [18].

The following conclusions can be made on the basis of the analysis of several international rankings (PIRLS, TIMSS, ICCS, PISA, the Social Progress Index; rankings of 30+ universities, published in June 2015 - May 2016):

- At the high school level, insufficient attention is drawn to sociopsychological competencies. The system of primary education, which has proven its efficiency in Russia, is hardly capable of preparing schoolchildren for their future responsible life. Russian primary education is built around the study of huge amounts of information, abstract in its essence. School graduates come to realize this drawback and become disillusioned with their secondary education. Extracurricular activities, organized by school teachers or psychologists can prevent their dissatisfaction;

- students of universities of technology cannot master sociopsychological competencies in their entirety, because these universities are not interested in developing these competencies. Students find it either hard or impossible to reflect on social problems, and their inability may provoke conflicts, negative emotions, and reduce their motivation towards educational and research activities; the quality of their knowledge deteriorates. 
This pattern may be prevented by a training programme, aimed at the development of sociopsychological competencies. The training programme can be integrated into professional disciplines (for example, "Fundamentals of Legislation and Social Interaction in the Construction Industry",

- Sociopsychological competencies of an urban planning specialist and manager represent the factor capable of boosting the quality of their interaction with urban residents, which can, in its turn, improve the overall life satisfaction in the contemporary urban environment.

\section{References}

1. L.A. Petrovskaya, edited by Yu.M. Smyslov, L.A. Petrovskaya, O.V. Solovyova, Introduction into Practical Social Psychology, 150-166 (1996)

2. A. Ishkov, T. Magera, Procedia Engineering, 117, pp. 148-153 (2015)

3. T.N. Magera, Izvestia of the Volgograd State Pedagogical University, 6 (91), 136-139 (2014)

4. E.A. Shnyrenkov, E.V. Romanova, Procedia Engineering, 117, pp. 336-341 (2015)

5. A.D. Ishkov, M.G. Leontev, Procedia Engineering, 117, pp. 142-147 (2015)

6. I.P. Pryadko, International Journal of Applied Engineering Research, 21, pp. 42147 $42152(2015)$

7. A.G. Gladyshev, V.N. Ivanov, E.S. Savchenko et al.; Municipal Management (Moscow, 2002)

8. E.N. Zaborova, edited by A.V. Tikhonov, Works of the 2nd Science Conf. "Social Management, Communications and Technologies for Social Projects" October 25-26, 2007 (2008)

9. E.A. Shnyrenkov, I.P. Pryadko, Procedia Engineering, 117, 325-330 (2015)

10. URL: http://www.pirls.org

11. URL: http://www.timss.org

12. URL: http://www.iea.nl/

13. International Civic and Citizenship Education Study. URL: http://www.iea.nl/iccs

14. W. Schulz, J. Ainley, J. Fraillon, B. Losito \& G. Agrusti, IEA International Civic and Citizenship Education Study 2016 Assessment Framework. (Springer, 2016)

15. URL: http://www.oecd.org/pisa/

16. URL: http://www.shanghairanking.com/

17. URL: http://www.socialprogressimperative.org/global-index/

18. A.D. Ishkov, N.G. Miloradova, A.Yu. Chernyshev, Procedia - Social and Behavioral Sciences, 171, pp. 765-770 (2015) 